\title{
Dessecação química e retardamento de colheita em soja visando à produção de sementes
}

\author{
Adriano Silveira BARBOSA ${ }^{1 *}$, Ildon Rodrigues do NASCIMENTO ${ }^{1}$, Rodrigo Ribeiro \\ FIDELIS $^{1}$, Sorane Moraes de SOUSA ${ }^{1}$, Joênes Mucci PELÚZIO ${ }^{1}$
}

\author{
${ }^{1}$ Programa de Pós-Graduação em Produção Vegetal, Universidade Federal do Tocantins, Gurupi, TO, Brasil. \\ *E-mail: adriano.sb27@gmail.com
}

Recebido em maio/2018; Aceito em agosto/2018.

\begin{abstract}
RESUMO: Estudos sobre o efeito da dessecação e retardamento de colheita, nas qualidades das sementes de soja, são escassos em cultivos sob baixa latitude. Objetivou-se avaliar o efeito da aplicação de dessecante em soja, avaliando o retardamento da colheita em duas cultivares, observando as respostas fisiológicas, químicas e produtividade das sementes. No ano agrícola 2016/17, foi realizado experimento em Gurupi-TO, em delineamento de blocos casualizados, com três repetições, sendo os tratamentos dispostos em esquema de parcelas subsubdivididas, alocados nas parcelas duas cultivares com tipos de crescimento diferentes (NA 8015 RR-indeterminado; M 8349 IPRO-determinado), nas subparcelas dois sistemas de manejo (com dessecação e testemunha) e nas subsubparcelas quatro épocas de colheita $\left(R_{8}, R_{8}+7, R_{8}+14, R_{8}+21\right)$. O dessecante utilizado foi herbicida com princípio ativo paraquat, na dosagem recomendada para a soja $\left(1,5 \mathrm{~L} \mathrm{ha}^{-1}\right)$, aplicado no estádio $\mathrm{R}_{7.2}$ da cultura. Após a colheita, as sementes foram submetidas aos testes de germinação em laboratório, emergência em campo, produtividade, teores de óleo e proteína dos grãos. Não houve efeito da dessecação química e do retardamento de colheita na composição química dos grãos. O retardamento da colheita afeta negativamente a germinação, emergência e produtividade das sementes. A cultivar M 8349 IPRO é mais tolerante ao retardamento de colheita.
\end{abstract}

Palavras-chave: épocas de colheita, Glycine max, herbicida dessecante.

\section{Chemical determination and delay of harvesting in soybeans for seed production}

\begin{abstract}
Studies on the effect of desiccation and crop delay on the qualities of soybean seeds are scarce in crops under low latitude. The objective of this study was to evaluate the effect of the application of desiccant in soybean, evaluating the delay of the harvest in two cultivars, observing the physiological, chemical and seed productivity responses. In the agricultural year 2016/17, an experiment was carried out in Gurupi-TO, a randomized complete block design, with three replications. The treatments were arranged in a sub-split plots scheme, with two cultivars with different growth types (NA 8015 RR-undetermined; M 8349 IPRO-determined) in the subplots two management systems (with desiccation and control) and in sub-subplots four harvest times $\left(\mathrm{R}_{8}, \mathrm{R}_{8}+7, \mathrm{R}_{8}+14, \mathrm{R}_{8}+21\right)$. The desiccant used was herbicide with paraquat active ingredient, at the recommended dosage for soybean $\left(1.5 \mathrm{~L} \mathrm{ha}^{-1}\right)$, applied at the $\mathrm{R}_{7.2}$ stage of the crop. After the harvest, the seeds were submitted to germination tests in the laboratory, field emergence, yield, oil content and grain protein. There was no effect of chemical desiccation and crop delay on the chemical composition of the grains. Harvest delay negatively affects seed germination, emergence and yield. The cultivar M 8349 IPRO is more tolerant to crop delay.
\end{abstract}

Keywords: harvest time, Glycine max, desiccant herbicide.

\section{INTRODUÇÃO}

No contexto mundial a soja está inserida economicamente como um dos principais produtos agrícolas. No Brasil, é a principal cultura em extensão de área e volume de produção, sendo responsável por 49,47\% de 225,6 milhões de toneladas da produção de grãos e por mais de $82 \%$ da produção de biodiesel (CONAB, 2018).

De acordo com dados da Conab (2018), o Brasil é o segundo produtor mundial de soja, que na safra 2017/2018 a produção foi cerca de 116,996 milhões de toneladas cultivadas em 35,1 milhões de hectares. Representando uma produtividade média nacional de $3.333 \mathrm{~kg} \mathrm{ha}^{-1}$. O produto da soja, representa ainda, fonte de proteína, utilizada principalmente na alimentação animal, e para produção de óleo.

Devido ao grande mercado da soja, busca-se o desenvolvimento científico agrícola para as regiões de baixa latitude dos cerrados, surgindo assim, uma nova fronteira agrícola denominada MATOPIBA, compreendendo as áreas de cerrados dos estados do Maranhão, Tocantins, Piauí e Bahia. Na safra 2017/18, a produção de soja na região foi cerca de 12,8 milhões de toneladas, que representa $11 \%$ da produção da oleaginosa no país (CONAB, 2018).

Desde a sua criação, em 5 de outubro de 1988, o estado do Tocantins não para de crescer no setor do agronegócio, uma vez que apresenta condições favoráveis como clima tropical, relevo predominantemente formado por planícies, pouca variação de altitude, vegetação predominante do tipo cerrado, possui grande potencial hídrico, apto para a tecnologia desenvolvida visando melhor produtividade do agronegócio. Essas características tornam o estado apto para investimento no setor do agronegócio (PACIEVITCH, 2018).

Crescendo assim grande demanda para $o$ alto investimento no setor agrícola do Tocantins, boa parte por causa da 
produtividade de soja, sendo assim, de suma importância que práticas de manejo fitotécnico, fitossanitário, melhoramento genético e qualidade das sementes sejam aprimoradas, desde o período de pré-plantio até o período de pós-colheita, para que não só a área plantada aumente como a produtividade por área (PELÚZIO et al., 2008).

As sementes de soja, segundo Toledo et al. (2012), apresentam maior capacidade de germinação e vigor quando atingem o ponto de maturação fisiológica. A partir desse ponto, a permanência da cultura no campo pode propiciar sensível redução na qualidade fisiológica das sementes, principalmente sob condições climáticas limitantes (altas temperaturas e umidades), ocasionando, produção de sementes com baixo potencial germinativo. Esta redução na qualidade fisiológica da semente tem sido verificada em quase todas as cultivares de soja que, apesar de altamente produtivas, apresentam problemas de qualidade, dificultando assim sua recomendação (TERASAWA et al., 2009).

Visando uma alternativa para minimizar esses problemas, estudos utilizando dessecação química em soja tem sido realizado. Os dessecantes têm por características desidratar as plantas e promover a antecipação da colheita de soja, sem alterar a produtividade por um período máximo de sete dias, além de reduzir os prejuízos decorrentes do ataque de fungos e pragas de final de ciclo (BEZERRA et al., 2014). Desta forma, as sementes não ficariam expostas às condições ambientais adversas como oscilações de temperatura e umidade, principalmente ao ataque de pragas de final de ciclo, que ocorrem no campo até o momento da colheita.

Neste contexto, o produtor de sementes teria, além de minimizada a perda por deterioração das sementes, antecipação, facilidade no manejo, planejamento de colheita, obtenção de sementes limpas, melhor qualidade, diminuição do custo, menor custo de secagem, redução das perdas de sementes causado pelo preenchimento de plantas na colhedora, devido a eliminação de plantas daninhas, evita os problemas que ocorrem com variedade de maturação desuniforme, reduz o tempo de hospedagem de doenças, que causam problemas na colheita e no beneficiamento (PEREIRA, 2015).
Diante do exposto, objetivou-se com este trabalho avaliar o efeito da aplicação de dessecante em soja cultivada sob baixa latitude, associado ou não a característica de retardamento da colheita em duas cultivares, observando as respostas fisiológicas e químicas e produtividade das sementes.

\section{MATERIAL E MÉTODOS}

No ano agrícola 2016/17, foi realizado experimento em dezembro na Universidade Federal do Tocantins (UFT), Campus de Gurupi ( $11^{\circ} 43^{\prime}$ 'de latitude Sul, $49^{\circ} 04^{\prime}$ de longitude Oeste e altitude de 280 metros). O clima da região é tropical, com moderada deficiência hídrica, a temperatura média anual é de $32^{\circ} \mathrm{C}$ no período de seca e de $26^{\circ} \mathrm{C}$ no período de chuvas, com precipitação anual média de $1804 \mathrm{~mm}$, sendo um verão chuvoso e um inverno seco (PACIEVITCH, 2018).

Os dados pluviométricos $(\mathrm{mm})$ e as temperaturas médias $\left({ }^{\circ} \mathrm{C}\right)$ diárias durante o período de condução do ensaio, são apresentados na Figura 1. Os resultados da análise química e física do material de solo da área experimental encontram-se na Tabela 1.

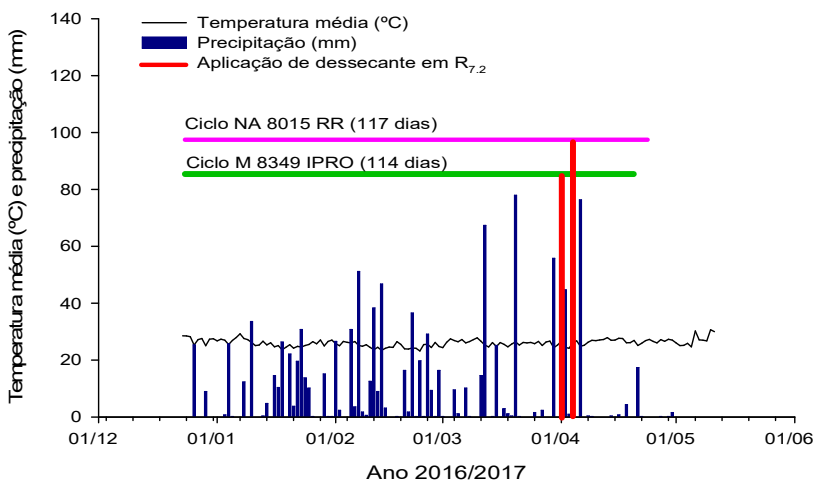

Figura 1. Dados pluviométricos $(\mathrm{mm})$ e as temperaturas médias $\left({ }^{\circ} \mathrm{C}\right)$ diárias, no ano agrícola 2016/2017. Fonte: Adaptado de INMET (2017).

Figure 1. Rainfall data $(\mathrm{mm})$ and average temperatures $\left({ }^{\circ} \mathrm{C}\right)$ per day, in the agricultural year 2016/2017. Source: Adaptedfrom INMET (2017).

Tabela 1. Resultados da análise química do solo na camada $0-20 \mathrm{~cm}$ para o local do experimento, antes da implantação da cultura. Table 1. Results of soil chemical analysis at the $0-20 \mathrm{~cm}$ layer for the experiment site, before culture implantation.

\begin{tabular}{|c|c|c|c|c|c|c|c|c|c|c|c|}
\hline $\mathrm{pH}^{1}$ & M.O. & $\mathrm{P}^{2}$ & K & K & $\mathrm{Ca}$ & $\mathrm{Mg}$ & $\mathrm{Al}$ & $\mathrm{H}+\mathrm{Al}$ & SB & CTC & V \\
\hline & dag. $\mathrm{kg}^{-1}$ & ---- & $\mathrm{m}^{-3}-----$ & ------ & -.-- & $--\mathrm{cmc}$ & $n^{-3}=$ & 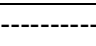 & & & $\%$ \\
\hline 4,6 & 2,0 & 9,7 & 66 & 0,17 & 1,6 & 0,7 & 0,10 & 3,40 & 2,47 & 5,87 & 42 \\
\hline Argila & & & & Silte & & & & Areia & & & \\
\hline 275 & & & & 50 & & & & 408 & & & \\
\hline
\end{tabular}

(1): CaCl2 0,01 mol L-1; (2): Extrator Mehlich.

O delineamento experimental utilizado foi de blocos casualizados, com três repetições, sendo os tratamentos dispostos em um esquema de parcelas subsubdivididas, sendo alocados nas parcelas dois cultivares de soja com tipos de crescimento diferentes (NA 8015 RR-indeterminado; M 8349 IPRO-determinado), nas subparcelas dois sistemas de manejo (com e sem aplicação do dessecante) e nas subsubparcelas quatro épocas de colheita $\left(\mathrm{R}_{8}, \mathrm{R}_{8}+7, \mathrm{R}_{8}+14, \mathrm{R}_{8}+21\right.$ dias $)$.

A parcela experimental foi composta por quatro fileiras de $5,0 \mathrm{~m}$ de comprimento, espaçadas por $0,45 \mathrm{~m}$. Na colheita, foram utilizadas plantas apenas das duas fileiras centrais, excluindo $0,5 \mathrm{~m}$ das extremidades de cada linha.

Após uma análise prévia do solo, foi realizada inicialmente a calagem, utilizando duas toneladas de calcário dolomítico
Filler/ha, que foi imediatamente incorporado ao solo, após a aplicação do calcário ocorre a neutralização do alumínio trocável, aumentando a saturação por bases (V\%).

Aos 30 dias após a correção, foram realizados os procedimentos de preparo do solo através das operações de aração, gradagem e sulcamento, foram realizadas na camada superficial $(0-20 \mathrm{~cm})$, tendo por base a análise do solo (Tabela 1). Conforme exigências da cultura, a recomendação de adubação foi de $120 \mathrm{~kg} \mathrm{ha}^{-1}$ de $\mathrm{P}_{2} \mathrm{O}_{5}$, seguida de adubação de cobertura $80 \mathrm{~kg} \mathrm{ha}^{-1}$ no estádio $\mathrm{V}_{2}$ (vegetativo) utilizando como fonte cloreto de potássio $(\mathrm{KCl})$.

No momento da semeadura, foi realizado o tratamento das sementes com fungicida e inseticida (princípio ativo piraclostrobina, tiofanato metílico e fipronil), seguido de 
inoculação das sementes com estirpes de Bradyrhizobium japonicum, sendo utilizado o produto turfoso na dosagem de

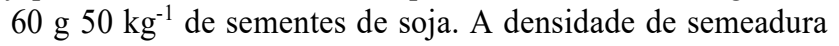
foi realizada com o intuito de se obter 14 plantas por metro, sendo efetuado o desbaste, quando necessário, aos 10 dias após a emergência.

Os tratos culturais para controle de pragas como as lagartas da soja (Anticarsia Gemmatalis) e falsa-medideira (Chrysodeixis includens) ao longo do ciclo da cultura utilizaram-se os inseticidas: metomil $\left(1,0 \mathrm{~L} \mathrm{ha}^{-1}\right)$, lambdacialotrina + chlorantraniliprole $\left(0,075 \mathrm{~L} \mathrm{ha}^{-1}\right)$ e teflubenzurom $\left(0,050 \mathrm{~L} \mathrm{ha}^{-1}\right)$. O manejo das doenças mancha alvo (Corynespora cassiicola) e antracnose (Colletotrichum truncatum) foi realizado com três aplicações de fungicidas: piraclostrobina + fluxapiroxade $\left(0,3 \mathrm{~L} \mathrm{ha}^{-1}\right.$ e $0,5 \mathrm{~L} \mathrm{ha}^{-1}$ de óleo mineral recomendado pelo fabricante) no estádio vegetativo $\mathrm{V}_{8}$, trifloxistrobina + protioconazol $\left(0,4 \mathrm{~L} \mathrm{ha}^{-1}\right.$ e $0,3 \mathrm{~L} \mathrm{ha}^{-1}$ de éster metílico de óleo de soja) no estádio reprodutivo $\mathrm{R}_{2} \mathrm{e}$ azoxistrobina + benzovindiflupir $\left(0,2 \mathrm{Kg} \mathrm{ha}^{-1}\right.$ e $0,6 \mathrm{~L} \mathrm{ha}^{-1}$ de óleo mineral) no estádio reprodutivo $\mathrm{R}_{4}$.

As plantas daninhas identificadas durante a execução do experimento foram capim-carrapicho (Cenchrus echinatus) e tiririca (Cyperus flavus), que foram controladas com glifosato (1,5 $\mathrm{L} \mathrm{ha}^{-1}$ e $0,5 \mathrm{~L} \mathrm{ha}^{-1}$ de óleo mineral recomendado pelo fabricante).

A dessecação foi realizada no momento em que as plantas estavam no estádio fenológico $\mathrm{R}_{7.2}$, com $51 \%$ e $75 \%$ de folhas e vagens amarelas (RITCHIE et al., 1982). O herbicida utilizado para a dessecação foi com princípio ativo paraquat, na dosagem de $1,5 \mathrm{~L} \mathrm{ha}^{-1}$ com adição de espalhante adesivo na concentração de $0,1 \%$ do volume de calda. Para aplicação do produto foi utilizado um pulverizador costal elétrico, visando obter uniformidade durante aplicação com a vazão de $150 \mathrm{~L}$ $\mathrm{ha}^{-1}$.

As plantas foram colhidas manualmente após apresentarem $95 \%$ das vagens maduras, ou seja, no estádio $\mathrm{R}_{8}$ da escala de Ritchie et al. (1982), e as parcelas avaliadas com retardamento, foram colhidas com 7, 14 e 21 dias após a colheita.

Depois de colhidas as plantas representativas de cada parcela, foram trilhadas em máquina trilhadora de sementes. Após a trilhagem das plantas, as sementes foram submetidas aos testes de germinação em laboratório, emergência em campo, produtividade, teores de óleo e proteína.

$\mathrm{O}$ teste de germinação foi realizado de acordo com as Regras para Análise de Sementes (MAPA, 2009), com a seguinte modificação: ao invés de 400 sementes utilizaram-se 200 sementes, em quatro sub-amostras de 50, para cada parcela, acondicionadas em rolo de papel germitest, umedecido com água na proporção de 2,5 vezes o peso do papel seco, em incubadora B.O.D. a $25^{\circ}$ C. As avaliações foram realizadas aos sete dias após a instalação dos testes.

Foi realizado o teste de emergência em campo na mesma área experimental onde foi realizado o ensaio, sendo utilizadas em cada parcela 200 sementes (quatro sub-amostras de 50), semeando-se 50 sementes em sulcos de 2,5 m de comprimento, espaçados de $0,45 \mathrm{~m}$ e à profundidade de $0,03 \mathrm{~m}$.

A avaliação da emergência baseou-se no total de plântulas que apresentava cotilédones inteiramente visíveis acima da superfície do solo, aos sete dias após a semeadura.
A produtividade de grãos foi obtida em gramas por parcela, em seguida convertidos para $\mathrm{kg} \mathrm{ha}^{-1}$, após correção da umidade para $13 \%$.

O teor de óleo foi obtido pelo método de Bligh; Dyer (1959), utilizando uma amostra por tratamento pesando 2,5 gramas do material seco e moído.

Para o teor de proteína foi utilizada a metodologia proposta por Kjeldahl encontrando o valor do nitrogênio total da amostra e posteriormente convertendo para proteína bruta por meio do fator 6,25 , utilizando uma amostra por tratamento pesando 0,5 gramas do material seco e moído (GALVANI; GAERTNER, 2006).

Os dados foram submetidos a análise de variância, após testar a normalidade dos dados pelo teste de Shapiro-Wilk, a $5 \%$ de significância. Em seguida, as médias das cultivares e manejo de dessecante foram comparadas pelo teste de ScottKnott, a 5\% de significância. Para as épocas de colheita, foram ajustados polinômios ortogonais. As análises estatísticas foram realizadas utilizando o programa estatístico SISVAR 5.0 (FERREIRA, 2011) e SIGMAPLOT software 12.5 .

\section{RESULTADOS}

\subsection{Análise de Variância}

$\mathrm{Na}$ análise de variância (Tabela 2), foi detectado efeito significativo para a interação tripla cultivares entre manejo de dessecante e épocas de colheita, indicando comportamento diferencial dos cultivares, em função das épocas de colheita e dos sistemas de manejo. Assim, foram realizados os desdobramentos. Os coeficientes de variação (CV) obtidos variaram entre 2,12 e 18,61 \% sendo considerados como baixo e médio, demonstrando boa precisão na execução do experimento (Tabela 2).

3.2. Comparação de médias

\subsubsection{Teor de proteína e de óleo}

Dentre os resultados para teor de proteína (Tabela 3) e teor de óleo (Tabela 4), para ambos os cultivares, não foram detectadas diferenças significativas entre os cultivares, em cada época de colheita e sistemas de manejo de dessecante.

\subsubsection{Teste padrão de Germinação e Emergência em campo}

A partir dos resultados apresentados com as médias de germinação em laboratório (Tabela 5), não foram detectadas diferenças significativas entre as cultivares, dentro da mesma época, com exceção da primeira época sem aplicação do dessecante, onde M 8349 IPRO apresentou diferença significativa quando comparada com a cultivar NA 8015 RR.

Com relação aos sistemas de manejo de dessecante, não houve diferença significativa apenas para o estádio R8, sendo que nas demais épocas (estádios) e em ambos os cultivares, houve maior germinação nas sementes cuja as plantas sofreram dessecação química, ou seja, com a dessecação é possível manter a qualidade fisiológica das sementes por mais tempo.

Para a emergência das plântulas (Tabela 6), foram detectadas diferenças significativas entre as cultivares, nas épocas $\mathrm{R}_{8}$ e $\mathrm{R}_{8}+7$, sem dessecante, e $\mathrm{R}_{8}$, com dessecante.

Com relação aos sistemas de manejo, com exceção do estádio $\mathrm{R}_{8}$, assim como ocorrido com a germinação (Tabela 5), em ambas as cultivares, houve maior emergência das plântulas com a aplicação do dessecante (Tabela 6). 
Tabela 2. Resumo da análise de variância das características teor de proteína (\%), teor de óleo (\%), germinação (\%), produtividade (kg ha-1) e emergência (\%), em dois cultivares de soja, em dois sistemas de manejo (com e sem dessecante), em quatro épocas de colheita, em GurupiTO, no ano agrícola 2016/2017.

Table 2. Summary of variance analysis of the characteristics of protein (\%), oil content (\%), germination (\%), productivity (kg ha $\left.\mathrm{k}^{-1}\right)$ and emergence (\%), in two soybean cultivars in two management systems (with and without desiccant) in four in harvest seasons Gurupi-TO, in the agricultural year 2016/2017.

\begin{tabular}{|c|c|c|c|c|c|c|}
\hline \multirow{2}{*}{$\mathrm{FV}^{1}$} & \multirow{2}{*}{$\mathrm{GL}^{2}$} & \multicolumn{4}{|c|}{ Quadrado Médio } & \multirow[b]{2}{*}{ Emergência } \\
\hline & & Proteína & Óleo & Germinação & Produtividade & \\
\hline Cultivares (a) & 1 & $3,15^{\mathrm{ns}}$ & $14,43^{\mathrm{ns}}$ & $408,33^{\text {ns }}$ & $4917401^{*}$ & $252,08^{*}$ \\
\hline Bloco & 2 & $1,54^{\mathrm{ns}}$ & $3,59^{\mathrm{ns}}$ & $78,25^{\mathrm{ns}}$ & $214306^{\mathrm{ns}}$ & $29,64^{\mathrm{ns}}$ \\
\hline Resíduo (a) & 2 & 6,13 & 4,95 & 104,08 & 57132 & 1,89 \\
\hline Sistemas de manejo (b) & 1 & $1,84^{\mathrm{ns}}$ & $2,67^{\mathrm{ns}}$ & $3745,3^{*}$ & $148^{\mathrm{ns}}$ & $2268,75^{*}$ \\
\hline Cultivares x Sistemas de manejo & 1 & $1,84^{\mathrm{ns}}$ & $0,39^{\text {ns }}$ & $12,00^{\text {ns }}$ & $207901^{\mathrm{ns}}$ & $4,08^{\mathrm{ns}}$ \\
\hline Resíduo (b) & 4 & 0,80 & 5,72 & 14,67 & 334931 & 17,35 \\
\hline Épocas (c) & 3 & $8,63^{\mathrm{ns}}$ & $3,01^{\mathrm{ns}}$ & $14829 *$ & $2022764 *$ & $10956,36^{*}$ \\
\hline Épocas x Sistemas de manejo & 3 & $0,55^{\text {ns }}$ & $10,46^{\text {ns }}$ & $859,78^{*}$ & $118009^{\text {ns }}$ & $308,36^{*}$ \\
\hline Época x Cultivar & 3 & $2,61^{\mathrm{ns}}$ & $9,79^{\text {ns }}$ & $150,78^{*}$ & $149749^{\text {ns }}$ & $58,58^{*}$ \\
\hline Época x Cultivar x Sistemas de manejo & 3 & $2,89^{\text {ns }}$ & $12,77^{\mathrm{ns}}$ & $38,44^{\mathrm{ns}}$ & $67132^{\mathrm{ns}}$ & $5,02 *$ \\
\hline Resíduo (c) & 24 & 3,13 & 6,64 & 39,92 & 123385 & 5,89 \\
\hline Total & 47 & & & & & \\
\hline MÉDIA & & 42,19 & 20,16 & 50,25 & 2559 & 35,29 \\
\hline $\mathrm{CV}^{3} \%(\mathrm{a})$ & & 5,87 & 11,04 & 18,30 & 9,34 & 3,90 \\
\hline $\mathrm{CV} \%(\mathrm{~b})$ & & 2,12 & 11,87 & 7,62 & 18,61 & 11,80 \\
\hline CV \%(c) & & 4,19 & 12,78 & 12,57 & 13,72 & 6,88 \\
\hline
\end{tabular}

(1): Fontes de variação; (2): Graus de liberdade; ${ }^{*}$ ): significativo pelo teste Scott-Knott a 5\% de probabilidade; (ns): não significativo; (3): coeficiente de variação.

Tabela 3. Médias do teor de proteína (\%) em dois cultivares de soja, com e sem dessecante (C/D e S/D), em quatro épocas de colheita, em Gurupi-TO, no ano agrícola 2016/2017.

Table 3. Averages of protein content (\%) in two soybean cultivars, with and without desiccant, in four harvest seasons, in Gurupi-TO, in the agricultural year 2016/2017.

\begin{tabular}{lcccc}
\hline \multirow{2}{*}{ Épocas } & \multicolumn{2}{c}{$\mathrm{NA} 8015 \mathrm{RR}$} & \multicolumn{2}{c}{$\mathrm{M} 8349 \mathrm{IPRO}$} \\
\cline { 2 - 5 } $\mathrm{R}_{8}$ & $\mathrm{C} / \mathrm{D}$ & $\mathrm{S} / \mathrm{D}$ & $\mathrm{C} / \mathrm{D}$ & $\mathrm{S} / \mathrm{D}$ \\
$\mathrm{R}_{8}+7$ & $41,26 \mathrm{Aa}$ & $40,61 \mathrm{Aa}$ & $40,07 \mathrm{Aa}$ & $41,63 \mathrm{Aa}$ \\
$\mathrm{R}_{8}+14$ & $41,88 \mathrm{Aa}$ & $42,48 \mathrm{Aa}$ & $41,95 \mathrm{Aa}$ & $42,98 \mathrm{Aa}$ \\
$\mathrm{R}_{8}+21$ & $42,01 \mathrm{Aa}$ & $43,16 \mathrm{Aa}$ & $43,73 \mathrm{Aa}$ & $42,64 \mathrm{Aa}$ \\
\hline
\end{tabular}

1-Médias entre as cultivares, seguidas pela letra maiúscula na linha, dentro da mesma época e para o mesmo sistema de manejo, pertencem ao mesmo grupo estatístico a 5\% de significância pelo teste de Scott-Knott a 5\% de probabilidade.2 -Médias entre os sistemas de manejo, seguidas pela letra minúscula na linha, dentro da mesma época e para a mesma cultivar, pertencem ao mesmo grupo estatístico a $5 \%$ de significância pelo teste de Scott-Knott a $5 \%$ de probabilidade.

Tabela 4. Médias do teor de óleo (\%) em duas cultivares de soja, com e sem dessecante (C/D e $S / D)$, em quatro épocas de colheita, em Gurupi-TO, no ano agrícola 2016/2017.

Table 4. Average oil content (\%) in two soybean cultivars, with and without desiccant, in four harvesting seasons, in Gurupi-TO, in the agricultural year 2016/2017.

\begin{tabular}{lcccc}
\multirow{2}{*}{ Épocas } & \multicolumn{2}{c}{$\mathrm{NA} 8015 \mathrm{RR}$} & \multicolumn{2}{c}{ M 8349 IPRO } \\
\cline { 2 - 5 } & $\mathrm{C} / \mathrm{D}$ & $\mathrm{S} / \mathrm{D}$ & $\mathrm{C} / \mathrm{D}$ & $\mathrm{S} / \mathrm{D}$ \\
\hline $\mathrm{R}_{8}$ & $20,26 \mathrm{Aa}$ & $20,26 \mathrm{Aa}$ & $16,00 \mathrm{Ab}$ & $21,33 \mathrm{Aa}$ \\
$\mathrm{R}_{8}+7$ & $18,66 \mathrm{Aa}$ & $19,40 \mathrm{Aa}$ & $20,76 \mathrm{Aa}$ & $21,80 \mathrm{Aa}$ \\
$\mathrm{R}_{8}+14$ & $19,20 \mathrm{Aa}$ & $19,73 \mathrm{Aa}$ & $23,43 \mathrm{Aa}$ & $19,20 \mathrm{Aa}$ \\
$\mathrm{R}_{8}+21$ & $19,73 \mathrm{Aa}$ & $19,63 \mathrm{Aa}$ & $21,33 \mathrm{Aa}$ & $21,80 \mathrm{Aa}$ \\
\hline
\end{tabular}

1-Médias entre as cultivares, seguidas pela letra maiúscula na linha, dentro da mesma época e para o mesmo sistema de manejo, pertencem ao mesmo grupo estatístico a 5\% de significância pelo teste de Scott-Knott a $5 \%$ de probabilidade. 2 -Médias entre os sistemas de manejo, seguidas pelo letra minúscula na linha, dentro da mesma época e para a mesma cultivar, pertencem ao mesmo grupo estatístico a 5\% de significância pelo teste de Scott-Knott a $5 \%$ de probabilidade.
Tabela 5. Médias de germinação em laboratório (\%) em dois cultivares de soja, com e sem dessecante $(\mathrm{C} / \mathrm{D}$ e $\mathrm{S} / \mathrm{D})$, em quatro épocas de colheita, em Gurupi- TO, no ano agrícola 2016/2017.

Table 5. Mean germination rates in two soybean cultivars, with and without desiccant, in four harvesting seasons, in Gurupi-TO, in the agricultural year 2016/2017.

\begin{tabular}{lcccc}
\hline \multirow{2}{*}{ Épocas } & \multicolumn{2}{c}{$\mathrm{NA} 8015 \mathrm{RR}$} & \multicolumn{2}{c}{$\mathrm{M} 8349 \mathrm{IPRO}$} \\
\cline { 2 - 5 } $\mathrm{C} / \mathrm{D}$ & $\mathrm{S} / \mathrm{D}$ & $\mathrm{C} / \mathrm{D}$ & $\mathrm{S} / \mathrm{D}$ \\
\hline $\mathrm{R}_{8}$ & $89,33 \mathrm{Aa}$ & $86,67 \mathrm{Ba}$ & $94,00 \mathrm{Aa}$ & $98,00 \mathrm{Aa}$ \\
$\mathrm{R}_{8}+7$ & $74,66 \mathrm{Aa}$ & $38,66 \mathrm{Ab}$ & $92,66 \mathrm{Aa}$ & $48,00 \mathrm{Ab}$ \\
$\mathrm{R}_{8}+14$ & $40,66 \mathrm{Aa}$ & $23,33 \mathrm{Ab}$ & $43,33 \mathrm{Aa}$ & $30,66 \mathrm{Ab}$ \\
$\mathrm{R}_{8}+21$ & $22,00 \mathrm{Aa}$ & $3,33 \mathrm{Ab}$ & $16,00 \mathrm{Aa}$ & $2,66 \mathrm{Ab}$ \\
\hline
\end{tabular}

1-Médias entre as cultivares, seguidas pela letra maiúscula na linha, dentro da mesma época e para o mesmo sistema de manejo, pertencem ao mesmo grupo estatístico a 5\% de significância pelo teste de Scott-Knott a 5\% de probabilidade.2 -Médias entre os sistemas de manejo, seguidas pela letra minúscula na linha, dentro da mesma época e para a mesma cultivar, pertencem ao mesmo grupo estatístico a $5 \%$ de significância pelo teste de Scott-Knott a $5 \%$ de probabilidade.

Tabela 6. Médias de emergência em campo (\%) em dois cultivares de soja, com e sem dessecante $(C / D$ e $S / D)$, em quatro épocas de colheita, em Gurupi-TO, no ano agrícola 2016/2017.

Table 6. Field emergence means (\%) in two soybean cultivars, with and without desiccant $(\mathrm{C} / \mathrm{D}$ and $\mathrm{S} / \mathrm{D})$, in four harvest seasons, in Gurupi-TO, in the agricultural year 2016/2017.

\begin{tabular}{lcccc}
\hline \multirow{2}{*}{ Épocas } & \multicolumn{2}{c}{$\mathrm{NA} 8015 \mathrm{RR}$} & \multicolumn{2}{c}{$\mathrm{M} 8349 \mathrm{IPRO}$} \\
\cline { 2 - 5 } $\mathrm{C} / \mathrm{D}$ & $\mathrm{S} / \mathrm{D}$ & $\mathrm{C} / \mathrm{D}$ & $\mathrm{S} / \mathrm{D}$ \\
\hline $\mathrm{R}_{8}$ & $71,66 \mathrm{Ba}$ & $68,00 \mathrm{Ba}$ & $82,00 \mathrm{Aa}$ & $79,33 \mathrm{Aa}$ \\
$\mathrm{R}_{8}+7$ & $51,66 \mathrm{Aa}$ & $23,33 \mathrm{Bb}$ & $54,00 \mathrm{Aa}$ & $30,00 \mathrm{Ab}$ \\
$\mathrm{R}_{8}+14$ & $29,33 \mathrm{Aa}$ & $11,33 \mathrm{Ab}$ & $30,66 \mathrm{Aa}$ & $14,00 \mathrm{Ab}$ \\
$\mathrm{R}_{8}+21$ & $8,00 \mathrm{Aa}$ & $0,66 \mathrm{Ab}$ & $10,00 \mathrm{Aa}$ & $0,66 \mathrm{Ab}$
\end{tabular}

1-Médias entre as cultivares, seguidas pela letra maiúscula na linha, dentro da mesma época e para o mesmo sistema de manejo, pertencem ao mesmo grupo estatístico a $5 \%$ de significância pelo teste de Scott-Knott a $5 \%$ de probabilidade. 2 -Médias entre os sistemas de manejo, seguidas pela letra minúscula na linha, dentro da mesma época e para a mesma cultivar, pertencem ao mesmo grupo estatístico a 5\% de significância pelo teste de Scott-Knott a $5 \%$ de probabilidade. 


\subsection{Produtividade}

Entre as cultivares, dentro da mesma época e mesmo sistema de manejo, mostra que não houve diferença entre os mesmos em $\mathrm{R}_{8}$. Por outro lado, nas demais épocas de colheita, a cultivar M 8349 IPRO foi mais produtiva sem e com dessecação, em $\mathrm{R}_{8}+7$, enquanto nas demais épocas houve diferença significativa apenas nos tratamentos sem dessecação, quando comparada com a cultivar NA 8015 RR (Tabela 7).

Tabela 7. Médias de produtividade $\left(\mathrm{kg} \mathrm{ha}^{-1}\right)$ em dois cultivares de soja, com e sem dessecante $(\mathrm{C} / \mathrm{D}$ e $\mathrm{S} / \mathrm{D})$, em quatro épocas de colheita, em Gurupi- TO, no ano agrícola 2016/2017.

Table 7. Average yields $\left(\mathrm{kg} \mathrm{ha}^{-1}\right)$ in two soybean cultivars, with and without desiccant, in four harvesting seasons, in Gurupi-TO, in the agricultural year 2016/2017.

\begin{tabular}{lcccc}
\hline & \multicolumn{3}{l}{$\mathrm{NA} 8015 \mathrm{RR}$} & \multicolumn{2}{l}{$\mathrm{M}$ 8349 IPRO } \\
\cline { 2 - 5 } Épocas & $\mathrm{C} / \mathrm{D}$ & $\mathrm{S} / \mathrm{D}$ & $\mathrm{C} / \mathrm{D}$ & $\mathrm{S} / \mathrm{D}$ \\
\hline $\mathrm{R}_{8}$ & 2822,21 & 2963,17 & 3136,28 & 3282,96 \\
& $\mathrm{Aa}$ & $\mathrm{Aa}$ & $\mathrm{Aa}$ & $\mathrm{Aa}$ \\
$\mathrm{R}_{8}+7$ & 2328,88 & 2355,84 & 3035,55 & 3151,10 \\
& $\mathrm{Ba}$ & $\mathrm{Ba}$ & $\mathrm{Aa}$ & $\mathrm{Aa}$ \\
$\mathrm{R}_{8}+14$ & 2081,48 & 1810,00 & 2561,48 & 2967,22 \\
& $\mathrm{Aa}$ & $\mathrm{Ba}$ & $\mathrm{Aa}$ & $\mathrm{Aa}$ \\
$\mathrm{R}_{8}+21$ & 1997,03 & 1560,00 & 2530,37 & 2374,81 \\
& $\mathrm{Aa}$ & $\mathrm{Ba}$ & $\mathrm{Aa}$ & $\mathrm{Aa}$
\end{tabular}

1-Médias entre as cultivares, seguidas pela letra maiúscula na linha, dentro da mesma época e para o mesmo sistema de manejo, pertencem ao mesmo grupo estatístico a $5 \%$ de significância pelo teste de Scott-Knott a $5 \%$ de probabilidade. 2 -Médias entre os sistemas de manejo, seguidas pela letra minúscula na linha, dentro da mesma época e para a mesma cultivar, pertencem ao mesmo grupo estatístico a $5 \%$ de significância pelo teste de Scott-Knott a $5 \%$ de probabilidade.

\subsection{Regressão Polinomial}

3.3.1. Germinação em laboratório

A regressão polinomial das médias de germinação em laboratório (\%) das cultivares NA 8015 RR (Figura 2) e M 8349 IPRO (Figura 3) em diferentes épocas de colheita $\left(R_{8}\right.$, $\left.\mathrm{R}_{8}+7, \mathrm{R}_{8}+14, \mathrm{R}_{8}+21\right)$, revelou queda contínua com o atraso na colheita a partir de R8, sendo esta queda menos acentuada com aplicação de dessecante.

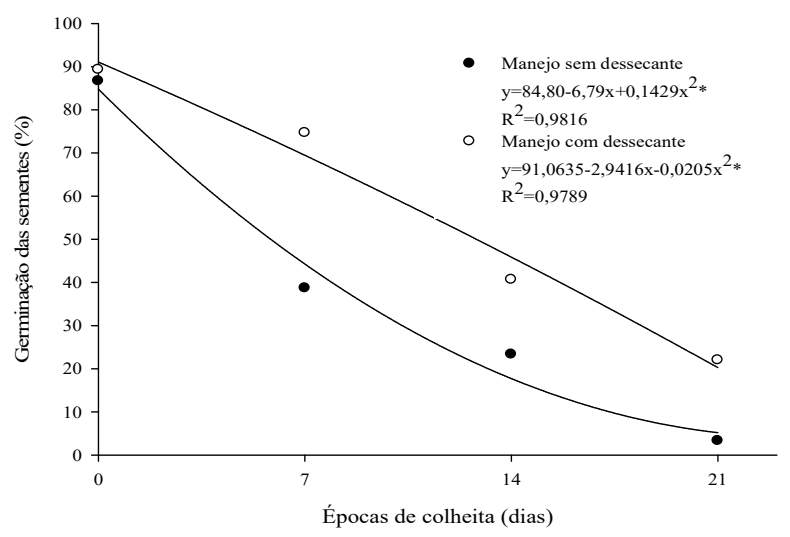

Figura 2. Médias de germinação das sementes em laboratório (\%) em função das épocas de colheita, sem dessecante e com dessecante, da cultivar NA 8015 RR, em Gurupi-TO, no ano agrícola 2016/2017.*significativo a 5\% de probabilidade pelo teste Scott-Knott. Figure 2. Average seed germination in the laboratory (\%) as a function of harvest times, without desiccant and with desiccant, of cultivar NA 8015 RR, in Gurupi-TO, in the agricultural year 2016/2017.*significant at $5 \%$ probability by the Scott-Knott test.

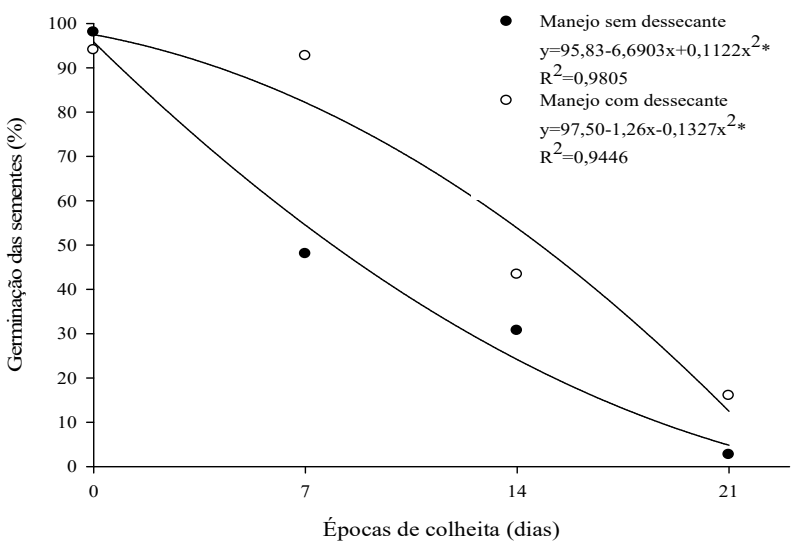

Figura 3. Médias de germinação das sementes em laboratório (\%) em função das épocas de colheita, sem dessecante e com dessecante, da cultivar M 8349 IPRO, em Gurupi-TO, no ano agrícola 2016/2017. *significativo a $5 \%$ de probabilidade pelo teste Scott-Knott.

Figure 3. Average seed germination in the laboratory (\%) as a function of harvest times, without desiccant and desiccant, of cultivar M 8349 IPRO, in Gurupi-TO, in the agricultural year 2016/2017.*significant at 5\% probability by the Scott-Knott test.

\subsubsection{Emergência em campo}

A regressão polinomial das médias de emergência em campo (\%) das cultivares NA 8015 RR (Figura 4) e M 8349 IPRO (Figura 5) em diferentes épocas de colheita $\left(\mathrm{R}_{8}, \mathrm{R}_{8}+7\right.$, $\left.\mathrm{R}_{8}+14, \mathrm{R}_{8}+21\right)$, revelou queda acentuada com o retardamento da colheita, sendo esta queda menos acentuada com a aplicação do dessecante.

\subsubsection{Produtividade}

A regressão polinomial das médias de produtividade $(\mathrm{kg}$ ha $^{-1}$ ) das cultivares NA 8015 RR (Figura 6) e M 8349 IPRO (Figura 7) em diferentes épocas de colheita $\left(\mathrm{R}_{8}, \mathrm{R}_{8}+7, \mathrm{R}_{8}+14\right.$, $\left.\mathrm{R}_{8}+21\right)$, revelou queda acentuada com o retardamento da colheita. A cultivar que apresenta tipo de crescimento determinado, atinge a maturação das vagens mais uniformemente, permitindo que as sementes se desenvolvessem nas melhores condições, promovendo o aumento da produtividade, ou seja, a época de plantio foi favorável para o cultivar determinado.

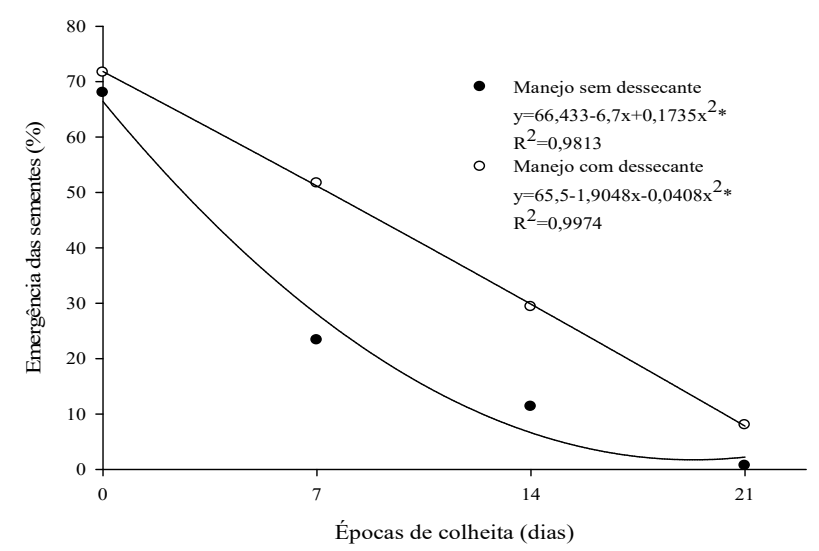

Figura 4. Médias de emergência das sementes em campo (\%) em função das épocas de colheita, sem dessecante e com dessecante, da cultivar NA 8015 RR, em Gurupi-TO, no ano agrícola 2016/2017. *significativo a $5 \%$ de probabilidade pelo teste Scott-Knott.

Figure 4. Seed emergence means in the field (\%) as a function of harvest times, without desiccant and with desiccant, of cultivar NA 8015 RR, in Gurupi-TO, in the agricultural year 2016/2017.

*significant at $5 \%$ probability by the Scott-Knott test. 


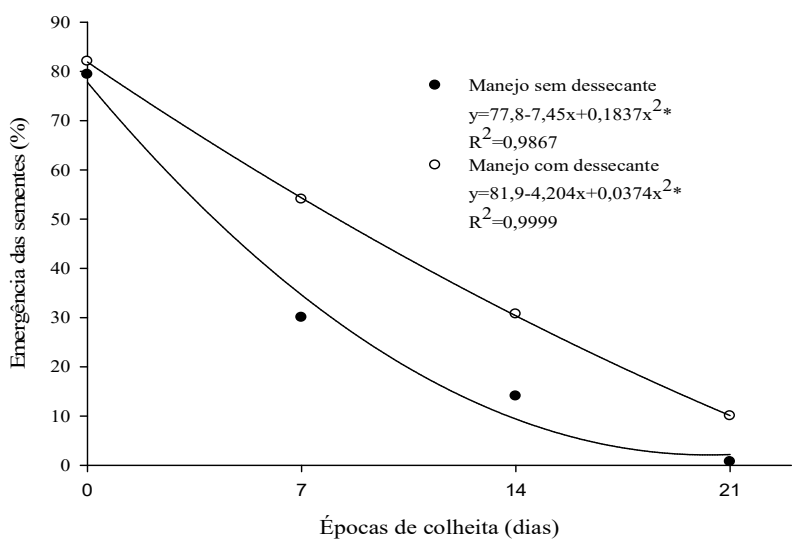

Figura 5. Médias de emergência das sementes em campo (\%) em função das épocas de colheita, sem dessecante e com dessecante, da cultivar M 8349 IPRO, em Gurupi-TO, no ano agrícola 2016/2017. *significativo a $5 \%$ de probabilidade pelo teste Scott-Knott.

Figure 5. Seed emergence means in field (\%) as a function of harvest times, without desiccant and desiccant, of cultivar M 8349 IPRO, in Gurupi-TO, in the agricultural year 2016/2017.*significant at 5\% probability by the Scott-Knott test.

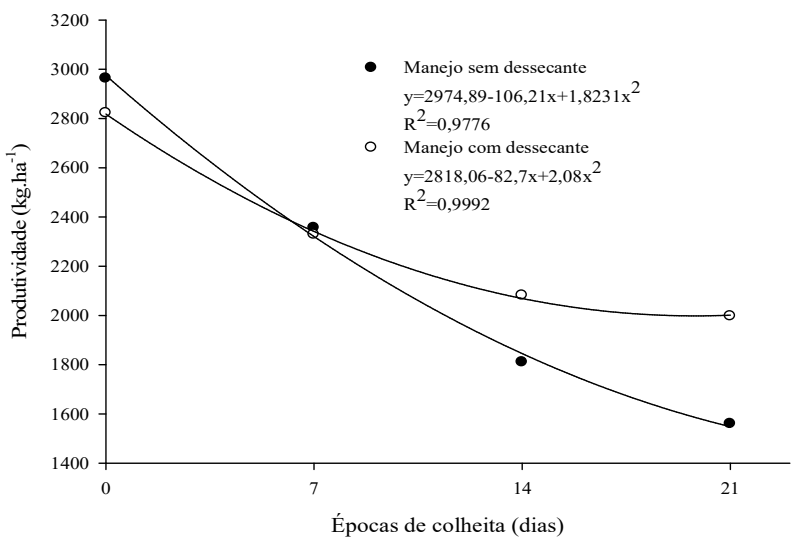

Figura 6. Médias de produtividade $\left(\mathrm{kg} \mathrm{ha}^{-1}\right)$ em função das épocas de colheita, sem dessecante e com dessecante, da cultivar NA 8015 RR, em Gurupi-TO, no ano agrícola 2016/2017. *significativo a 5\% de probabilidade pelo teste Scott-Knott.

Figure 6. Average yields $\left(\mathrm{kg} \mathrm{ha}^{-1}\right)$ as a function of harvest times, without desiccant and desiccant, of cultivar NA 8015 RR, in GurupiTO, in the agricultural year $2016 / 2017 .{ }^{*}$ significant at $5 \%$ probability by the Scott-Knott test.

\section{DISCUSSÃO}

Para teor de proteína (Tabela 3), estes resultados estão em concordância com aqueles obtidos por Lacerda et al. (2005), que verificaram similaridade no conteúdo proteico nas sementes em dessecação química realizada no estádio $\mathrm{R}_{7}$.

Dados observados por Bezerra et al. (2014) com aplicação de dessecante no período de maturação fisiológica, as cultivares testadas apresentaram teores de proteína dentro do padrão esperado, não diferenciando estatisticamente entre si. Segundo Sediyama et al. (2015) a temperatura não está associada com o conteúdo de proteína e tem pouco efeito na porcentagem encontrada na semente.

Para o teor de óleo (Tabela 4), Gomes et al. (2003) observaram em sementes de soja com e sem aplicação de paraquat, teores de 20,12 e 22,06 \%, respectivamente, não havendo diferenças estatísticas significativas entre si. Marcandalli et al. (2011), também não verificaram efeito da dessecação química no teor de óleo das sementes. Segundo
Finoto et al. (2017), com relação ao teor de óleo das sementes, os valores atingem um máximo durante a fase de maturação da semente e indica que a dessecação realizada do estádio $\mathrm{R}_{7.2}$ não afeta o conteúdo de óleo e proteína das sementes.

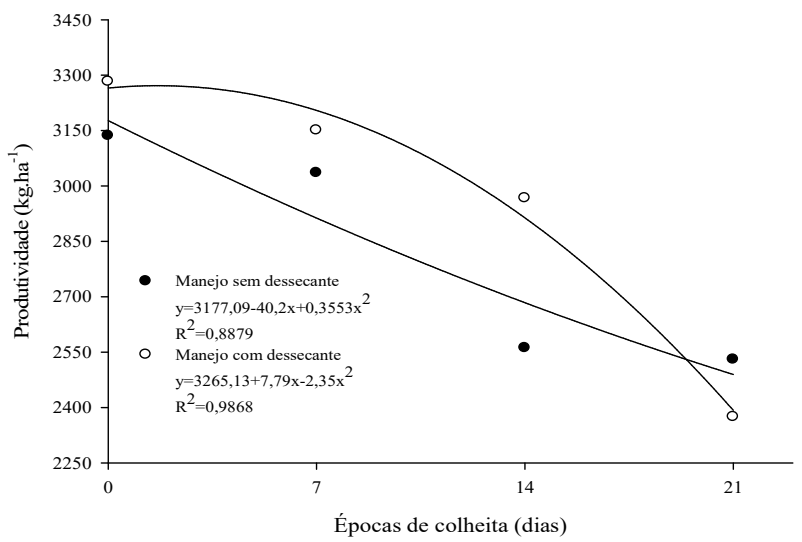

Figura 7. Médias de produtividade $\left(\mathrm{kg} \mathrm{ha}^{-1}\right)$ em função das épocas de colheita, sem dessecante e com dessecante, da cultivar M 8349 IPRO, em Gurupi-TO, no ano agrícola 2016/2017. *significativo a 5\% de probabilidade pelo teste Scott-Knott.

Figure 7. Productivity averages $\left(\mathrm{kg} \mathrm{ha}^{-1}\right)$ as a function of harvest times, without desiccant and desiccant, of cultivar M 8349 IPRO, in Gurupi-TO, in the agricultural year 2016/2017.*significant at 5\% probability by the Scott-Knott test.

Quando comparados os tratamentos entre as cultivares pode-se observar que não houve diferença estatística tanto para teor de proteína e óleo, pois as cultivares apresentam alta porcentagens desses teores, devido serem cultivares altamente produtivas na região de baixa latitude. Dados observados por Lopes et al. (2016) apresentam similaridade de comportamento para a grande maioria das cultivares cultivadas em baixas latitudes, com relação as médias dos teores de óleo e proteína.

Para teste padrão de germinação e emergência (Tabelas 5 e 6), segundo Terasawa et al. (2009), após atingir a maturidade fisiológica, as sementes ficam expostas ao ataque de pragas, microrganismos e fatores climáticos, até atingir o teor de umidade ideal para a colheita. Durante este período, inicia-se um processo de deterioração que afetará diretamente a qualidade fisiológica dos lotes de sementes.

Segundo Lamego et al. (2013), a aplicação de dessecantes em estádios mais precoces na cultura da soja provoca melhoria no poder germinativo das sementes, em virtude do menor tempo de permanência das sementes no campo, reduzindo a exposição das mesmas às condições ambientais desfavoráveis, tais como temperatura, umidade relativa do ar, precipitações pluviométricas e os severos ataques de pragas.

A cultivar M 8349 IPRO apresentou, nos estádios iniciais de colheita, uma melhor qualidade das sementes em relação ao cultivar NA 8015 RR (Tabelas 5 e 6). Tal fato pode ter ocorrido em função de M8349 IPRO ter tipo de crescimento determinado, que permitiu a mesma atingir mais rapidamente a maturação fisiológica, reduzindo o tempo de exposição de suas sementes as altas temperaturas e pluviosidades (Figura 1) nos estádios a partir de $\mathrm{R}_{7}$

Segundo Meneghello (2014), elevadas temperaturas e pluviosidades na fase de maturação, podem atrasar a colheita e atuar de forma direta sobre o metabolismo das plantas, afetando, por exemplo, respiração, transpiração, síntese e 
translocação de fotoassimilados contribuindo para acelerar a degradação fisiológica das sementes.

Para produtividade (Tabela 7), com relação aos sistemas de manejo de dessecante, não foram detectadas diferenças significativas para ambos os cultivares, ou seja, é possível antecipar a colheita sem alterar a produtividade, quando colhidas na mesma época.

Esses dados corroboram com Lacerda et al. (2005), onde observaram que herbicidas dessecantes aplicados nos estádios em que já ocorreu a maturação fisiológica das sementes não interferiram na produtividade da cultura da soja.

Guimarães et al. (2012) concluíram que a dessecação de plantas de soja em pré-colheita, com os herbicidas e estádios fenológicos estudados, não reduziu a produtividade.

Segundo Pereira et al. (2015) a aplicação de dessecantes na pré-colheita de cultivares de soja de tipo determinado e indeterminado a partir do estádio $R_{7.1}$ não proporcionou redução de produtividade da cultura, portanto pode-se recomendar a dessecação pré-colheita neste estádio fenológico.

Bezerra et al. (2014) afirmam que as maiores produtividades foram observadas nos tratamentos com dessecação na maturação fisiológica e na colheita sem dessecação, enquanto nos outros tratamentos com dessecação antes de $\mathrm{R}_{7}$ houve perdas significativas na produtividade.

Kappes et al. (2008) constataram que a dessecação realizada com diquat ou paraquat no estádio $R_{7}$ não resultou em diminuição no rendimento final da cultura, pois quando realizada adequadamente, na maturação fisiológica, haverá uniformidade na maturação das plantas e antecipação da colheita, sem afetar o potencial produtivo.

Para regressão polinomial de germinação, observa-se nos gráficos (Figuras 2 e 3) que a porcentagem de germinação alcançou valor máximo na primeira época de colheita, tanto para as cultivares sem e com manejo dessecante, devido as condições favoráveis para obter essa qualidade fisiológica. $\mathrm{Na}$ colheita em $\mathrm{R}_{8}$, com dessecação manteve-se a qualidade fisiológica de germinação quando comparado com a testemunha, pois não apresentou diferença significativa nessa mesma época de colheita.

Com o retardamento da colheita essa qualidade perde sua potencialidade, sendo que nos tratamentos com dessecante a qualidade fisiológica teve queda menos acentuada que na testemunha, pois a colheita foi antecipada e as sementes ficaram menos tempo no campo, diminuindo a deterioração devido à exposição no campo por longo período de tempo.

Segundo Tsukahara et al. (2016), após atingir a maturidade fisiológica, as sementes ficam expostas ao ataque de pragas, microrganismos e fatores climáticos, até atingir o teor de umidade ideal para a colheita. Durante este período, inicia-se um processo de deterioração que afetará diretamente a qualidade fisiológica dos lotes de sementes, essa deterioração das sementes aumenta consideravelmente devido exposição às condições adversas de temperatura e umidade relativa, resultando em menor vigor das sementes.

Os dados obtidos no presente trabalho corroboram com dados de Xavier et al. (2015) onde relatam que o efeito negativo foi observado, com retardamento de colheita, após a maturação fisiológica, não alcançando em média, o mínimo aceitável de germinação necessário para comercialização de um lote de sementes. Destacando a importância da época adequada de colheita, principalmente nas regiões de baixa latitude. Resultados que concordam com a afirmação de Holtz;
Reis (2013) sobre a influência das variações climáticas na qualidade de sementes.

Resultados semelhantes foram detectados por Pelúzio et al. (2008), que também observaram queda na taxa de germinação de sementes com o atraso de colheita, utilizando dessecante em diferentes estádios de aplicação. Os autores relatam ainda que as maiores taxas de germinação e vigor foram obtidas com a dessecação realizada no período de maturação fisiológica. Outros autores também encontraram redução da germinação de sementes de soja com o retardamento da colheita, como Sediyama et al. (2015) e Toledo et al. (2012).

Entretanto, a permanência das sementes no campo após a maturação, reduziu a germinação e o vigor das sementes, provavelmente, por efeito das altas temperaturas (Figura 1), onde pode ser observado que após o estádio $\mathrm{R}_{7}$ ainda tem altas incidências de pluviosidade e temperaturas acima de $30^{\circ} \mathrm{C}$.

A cultivar M 8349 IPRO com tipo de crescimento determinado teve melhores médias de germinação, quando comparado com a cultivar NA 8015 RR com tipo de crescimento indeterminado, certamente as diferenças detectadas podem ser atribuídas a constituição genética dos materiais avaliados, pois com o crescimento determinado permite-se atingir mais uniformemente a maturação fisiológica, favorecendo ao cultivar menor taxa de deterioração devido às condições adversas.

Dados observados por Bezerra et al. (2014) foram que as sementes de soja provenientes de cultivares de tipos de crescimento determinado apresentam médias de qualidade fisiológica de germinação superior ao de cultivares de tipos indeterminado, quando dessecadas no período de maturação fisiológica $\left(\mathrm{R}_{7}\right)$.

Para regressão polinomial de emergência, observa-se nos gráficos (Figuras 4 e 5) maior potencial de emergência em campo na primeira época de colheita $\left(R_{8}\right)$ e queda gradual acentuada nas épocas seguintes, para ambos as cultivares.

Os dados obtidos com emergência em campo corroboram com dados obtidos por Santos et al. (2000), onde as maiores porcentagens foram obtidas com sementes de plantas colhidas na maturação fisiológica. Observa-se ainda que à semelhança do que ocorreu no teste de germinação, a emergência foi afetada pelo atraso da colheita.

$\mathrm{O}$ retardamento de colheita aumenta a porcentagem de embebição de água pelas sementes e reduz a porcentagem de germinação, vigor e emergência das plântulas (CARVALHO et al., 2009). Segundo Minuzzi et al. (2010) com o atraso na colheita, ocorre redução qualitativa dos parâmetros fisiológicos por efeito do processo respiratório das sementes, que afetam a germinação, emergência e o vigor das sementes.

Dados observados por Daltro et al. (2010) afirmam que a antecipação da colheita diminui o período de exposição das sementes às intempéries climáticas durante a fase de campo, reduzindo a incidência de danos prejudiciais as sementes, sendo ideal utilizar a primeira época de colheita para adquirir as melhores qualidades. A cultivar M 8349 IPRO foi mais tolerante ao retardamento de colheita, devido suas características de cultivar determinado, atingindo a maturação das vagens mais precocemente, permitindo que as sementes se desenvolvessem nas melhores condições, promovendo melhores qualidades fisiológicas de emergência.

Já a cultivar NA 8015 RR, de tipo de crescimento indeterminado, por sua vez, apresentou uma maior queda na emergência das plântulas, devido ao período maior de maturação das vagens, que resultou em maturação menos 
uniforme dos grãos e uma menor qualidade fisiológica dos mesmos, devido exposição das sementes por mais tempo no campo, como pode ser observado no gráfico da Figura 1 onde após a dessecação em $\mathrm{R}_{7.2}$ as plantas ficaram expostas a chuvas acima de $70 \mathrm{~mm}$ e temperaturas elevadas acima de $30^{\circ} \mathrm{C}$.

A porcentagem média de germinação apresenta-se superior à porcentagem média de emergência, pois as conduções de tratamentos dos testes apresentam condições favoráveis para laboratório e condições menos favoráveis para o campo.

Assim, quanto à germinação em laboratório, as sementes ficam em ambiente mais favorável com maior umidade, dentro de câmara incubadora B.O.D, com condições climáticas controladas tendendo a ter maiores porcentagens, enquanto a emergência de plântulas em campo, as sementes ficam em ambiente menos favorável com menor umidade, debaixo do solo, com condições climáticas não controladas tendendo a ter menores porcentagens quando comparadas com o teste de germinação.

Outro fator desfavorável para emergência de plântulas em campo são os microrganismos do solo que atuam na transformação e decomposição da matéria orgânica, dificultando a emergência das plântulas nesse ambiente.

Para regressão polinomial de produtividade, observa-se nos gráficos (Figuras 6 e 7) que na primeira época de colheita a produtividade de ambos as cultivares está na faixa ideal, sendo que com o retardamento da colheita a produtividade começa a diminuir. A produtividade está diretamente ligada ao rendimento da soja, e para obter excelente produtividade, deve ser necessário que a colheita seja executada na sua faixa ideal, que é no estágio $\mathrm{R}_{8}$. Colheitas executadas após o estágio ideal tendem a ter perdas na produtividade pois podem ocorrer condições desfavoráveis com as sementes expostas no campo, além da debulha natural.

Segundo Tsukahara et al. (2016) as maiores perdas de produtividade ocorrem em ambientes com alta frequência de precipitações pluviais, altas temperaturas e elevada radiação solar global. Esses dados corroboram estes resultados, pois com a exposição das sementes no campo, após o período ideal de colheita, ocorreram precipitações pluviais intensas, altas temperaturas e alta incidência solar (Figura 1), com temperaturas médias em torno de $30^{\circ} \mathrm{C}$.

Outro fator importante denominado como debulha natural, ocorre quando a planta permanece em ponto de colheita no campo por mais tempo do que o necessário, ocasionando maior probabilidade da ocorrência de abertura das vagens, seja por fatores genéticos de cada cultivar ou induzida (ventos fortes, chuvas torrenciais, entre outros) acarretando a deiscência parcial ou total dos grãos, sendo que na colhedora a probabilidade de perdas significativas torna-se maior (TSUKAHARA et al., 2016).

Dados observados por Borges et al. (2006) durante a safra de 2001/2002, em Ponta Grossa, PR, ocorreram perdas médias de produtividade da ordem de $1.826 \mathrm{~kg} \mathrm{ha}^{-1}$ de quatro cultivares de soja, após 45 dias de atraso da colheita, ressaltando a importância de colher no período ideal para evitar as perdas de produtividade.

Dados observados por Pereira et al. (2015) mostram que a produtividade de sementes de soja foi superior para o tratamento oriundo da dessecação pré-colheita realizada no estádio $\mathrm{R}_{7.1}$, com o uso do dessecante paraquat, pois a aplicação do herbicida antecipou a colheita em seis dias. As plantas da testemunha permaneceram por mais tempo no campo, o que pode ter favorecido a deiscência de vagens e consequentemente a menor produtividade.

Daltro et al. (2010) e Guimarães et al. (2012), verificaram que o uso da dessecação química antes da maturidade fisiológica (estádios de desenvolvimento $\mathrm{R}_{6}$ ou $\mathrm{R}_{6.5}$ ) com o uso dos dessecantes paraquat também não afetam a produtividade da soja, quando colhidos na época ideal.

Para as demais épocas de colheita $\left(\mathrm{R}_{8}+7, \mathrm{R}_{8}+14\right.$ e $\left.\mathrm{R}_{8}+21\right)$, a produtividade teve perdas significativas em consequência do atraso da colheita, influenciadas pelas condições climáticas após o estádio $\mathrm{R}_{8}$ e pelas características genéticas de cada cultivar. Segundo dados observados por Tsukahara et al. (2016) as maiores perdas de produtividade de soja ocorrem em ambientes com alta frequência de precipitações pluviais, altas temperaturas e elevada radiação solar global.

Pereira et al. (2015) afirma que em condição de atraso de colheita as sementes ficam mais tempo no campo e expostas a danos por umidade, ao ataque de pragas e infecção de patógenos. Desta forma, observou-se que o atraso de colheita proporcionou redução da produtividade.

A cultivar M 8349 IPRO foi mais tolerante quando comparada com a cultivar NA $8015 \mathrm{RR}$, pelo fato da primeira ser cultivar de tipo de crescimento determinado atingiu a maturação das vagens mais precocemente, permitindo que as plantas se desenvolvessem nas melhores condições, aumentando assim a produtividade, devido também a época de semeadura que favoreceu a cultivar, permitindo que as sementes ficassem menos dias expostas no campo.

\section{CONCLUSÕES}

Não há efeito da dessecação química e do retardamento de colheita na composição química dos grãos.

$\mathrm{O}$ retardamento da colheita afeta negativamente a germinação, emergência e produtividade das sementes.

A cultivar M 8349 IPRO é mais tolerante ao retardamento de colheita.

\section{AGRADECIMENTOS}

Agradeço ao $\mathrm{CNPq}$ e a Capes por ter fornecido a bolsa da pesquisa durante a sua execução, número do processo 1588971.

\section{REFERÊNCIAS}

BEZERRA, A. R. G.; SEDIYAMA, T.; NOBRE, D. A. C.; FERREIRA, L. V.; SILVA, F. C. S.; SILVA, A. F.; ROSA, D. P. Efeito da dessecação com etefão na produção e qualidade da soja. Revista de Ciências Agrárias, Lisboa, v. 37, n. 3, p. 312-319, 2014.

BLIGH, E. G.; DYER, W. J. A rapid method for total lipid extraction and purification. Canadian Journal of Biochemistry and Physiology, Ottawa, v. 37, n. 8, p. 911917, 1959. DOI: https://dx.doi.org/10.1139/059-099

BORGES, I. O.; MACIEL, A. J. S.; MILAN, M. Programa computacional para o dimensionamento de colhedoras considerando a pontualidade na colheita de soja. Engenharia Agrícola, v. 26, n. 1, p. 131-141, 2006.

CARVALHO, L. F.; SEDIYAMA, C. S.; REIS, M. S.; DIAS, D. C. F. S.; MOREIRA, M. A. Influência da temperatura de embebição da semente de soja no teste de condutividade elétrica para avaliação da qualidade fisiológica. Revista Brasileira de Sementes, Londrina, v. 31, n. 1, p. 009-017, 2009. DOI: https://dx.doi.org/10.1590/S010069162006000100015 
CONAB COMPANHIA NACIONAL DE ABASTECIMENTO. Quinto Levantamento da Safra de Grãos 2017/2018. Disponível em: <http://www.conab.gov.br/OlalaCMS/uploads/arquivos/18_02_08_17_09 36 fevereiro_2018.pdf $>$. Acesso em: 15 mar 2018.

DALTTRO, E. M. F.; ALBUQUERQUE, M. C. F.; FRANÇA NETO, J. B.; GUIMARÃES, S. C.; GAZZIERO, D. L. P.; HENNING, A. A. Aplicação de dessecantes em précolheita: efeito na qualidade fisiológica de sementes de soja. Revista Brasileira de Sementes, Londrina, vol. 32, n. $1, \quad$ p. $111-122,2010$. DOI: http://dx.doi.org/10.1590/S0101-31222010000100013

FERREIRA, D. F. Sisvar: A computer statistical analysis system. Ciência e Agrotecnologia, Lavras, v. 35, n. 6, p. 1039-1042, 2011. DOI: http://dx.doi.org/10.1590/S141370542011000600001

FINOTO, E. L.; SEDIYAMA, T.; ALBUQUERQUE, J. A. A.; SOARES, M. B. B.; GALLI, J. A.; CORDEIRO JUNIOR, P. S.; MENEZES, P. H. S. Antecipação e retardamento de colheita nos teores de óleo e proteína das sementes de soja, cultivar Valiosa RR. Scientia Agropecuaria, Trujillo, v. 8, n. 2, p. 99-107, 2017. DOI: http://dx.doi.org/10.17268/sci.agropecu.2017.02.02

GALVANI, F.; GAERTNER, E. Adequação da Metodologia Kjeldahl para determinação de Nitrogênio Total e Proteína Bruta. Corumbá: Embrapa Pantanal, 2006. 9 p. (Circular técnica, 63)

GOMES, J. C.; SOARES, L. F.; PEREIRA, C. A. S; JHAM, G. N. Efeito do dessecante paraquat na qualidade da fração lipídica da soja. Ciência e Agrotecnologia, Lavras, v. 27, n. $1, \quad$ p. $178-184, \quad 2003$. DOI: http://dx.doi.org/10.1590/S1413-70542003000100022

GUIMARÃES, V. F.; HOLLMANN, M. J.; FIOREZE, S. L.; ECHER, M. M.; COSTA, A. C. P. R.; ANDREOTTI, M. Produtividade e qualidade de sementes de soja em função de estádios de dessecação e herbicidas. Planta Daninha, Viçosa, v. 30, n. 3, p. 567-573, 2012. DOI: http://dx.doi.org/10.1590/S0100-83582012000300012

HOLTZ, V., REIS, E. F. Perdas na colheita mecanizada de soja: uma análise quantitativa e qualitativa. Revista Ceres. Viçosa, v. 60, n. 3, p. 347-353, 2013.

INMET. Instituto Nacional de Meteorologia. 2017. Disponível em $<\quad$ http://www.inmet.gov.br/sonabra/pg_iframe.php? codEst $=$ A019\&mesAno $=2017>$ Acesso em 08 dezembro de 2017.

KAPPES, C.; ORSI, J. V. N.; JESUS JÚNIOR, A. M.; CARVALHO, M. A. C. Efeitos dos dessecantes diquat e paraquat no potencial produtivo da cultura da soja. Cultura Agronômica, v. 17, n. 1, p. 57-67, 2008.

LACERDA, A. L. S.; LAZARINI, E.; SÁ, M. E.; VALÉRIO FILHO, W. V. Efeitos da dessecação de plantas de soja no potencial fisiológico e sanitário das sementes. Bragantia, Campinas, v. 64, n. 3, p. 447-457, 2005. DOI: http://dx.doi.org/10.1590/S0104-56872005000300014

LAMEGO, F. P.; GALLON, M.; BASSO, C. J.; KULCZYNSKI, S. M.; RUCHEL, Q.; KASPARY, T. E.; SANTI, A. L. Dessecação pré-colheita e efeitos sobre a produtividade e qualidade fisiológica de sementes de soja. Planta Daninha, Viçosa, v. 31, n. 4, p. 929-938, 2013. DOI: 83582013000400019

LOPES, J. A. M.; PELÚZIO, J. M.; MARTINS, G. S. Teor de proteína e óleo em grãos de soja, em diferentes épocas de plantio para fins industriais. Tecnologia \& Ciência Agropecuária, João Pessoa, v. 10, n. 3, p. 49-53, 2016.

MAPA_MINISTÉRIO DA AGRICULTURA, PECUÁRIA E ABASTECIMENTO. Regras para análise de sementes. Brasília, 2009. 365 p.

MARCANDALLI, L. H.; LAZARINI, E.; MALASPINA, I. C. Épocas de aplicação de dessecantes na cultura da soja: qualidade fisiológica de sementes. Revista Brasileira de Sementes, Londrina, v. 33, n. 2, p. 241-250, 2011. DOI http://dx.doi.org/10.1590/S0101-31222011000200006

MENEGHELLO, G. E. Qualidade de Sementes: Umidade e Temperatura. Seed News a revista internacional de sementes, 2014. Disponível em: $<$ http://www.seednews.inf.br/_html/site/content/reportage m_capa/imprimir.php?id=208>. . Acesso em: 15/02/2018.

MINŪZZI, A.; BRACCINI, A. de L. e; RANGEL, M. A. S.; SCAPIM, C. A.; BARBOSA, M. C.; ALBRECHT, L. P. Qualidade de sementes de quatro cultivares de soja, colhidas em dois locais no estado do Mato Grosso do Sul. Revista Brasileira de Sementes, Londrina, v. 32, n. 1, p. 176-185, 2010. DOI: http://dx.doi.org/10.1590/S010131222010000100020

PACIEVITCH, T. Geografia do Tocantins. Info Escola, 2018. Disponível em: $<$ https://www.infoescola.com/geografia/geografia-do-tocantins/>. 2017. Acesso em: 03 ago 2018.

PELÚZIO, J. M.; RAMO, L. N.; FIDELIS, R. R.; AFFÉRRI, F. S.; CASTRO NETO, M. D.; CORREIA, M. A. R. Influência da dessecação química e retardamento de colheita na qualidade fisiológica de sementes de soja no sul do estado do Tocantins. Bioscience Journal, Uberlândia, v. 24, n. 2, p. 77-82, 2008.

PEREIRA, T.; COELHO, C. M. M.; SOUZA, C. A.; MANTOVANI, A.; MATHIAS, V. Dessecação química para antecipação de colheita em cultivares de soja. Semina: Ciências Agrárias, Londrina, v. 36, n. 4, p. 2383-2394, 2015. DOI: http://dx.doi.org/10.5433/16790359.2015v36n4p2383

RITCHIE, S.; HANWAY, J. J.; THOMPSON, H. E. How a Soybean Plant Develops. Ames: Iowa State University of Science and Technology, Cooperative Extension Service, 1982. $20 \mathrm{p}$.

SANTOS, C. M.; CHAGAS, R. C. S.; SANTOS, V. L. M.; CARVALHO, J. A. Efeito do retardamento da colheita na qualidade das sementes de soja dessecadas com paraquat. Revista Brasileira de Herbicidas, Uberlândia, v. 1, n. 1, p. 39-44, 2000. DOI: https://dx.doi.org/10.7824/rbh.v1i1.313

SEDIYAMA, T.; SILVA, F. L.; BORÉM, A. Soja - Do plantio a colheita, Viçosa, p. 333, 2015.

TERASAWA, J. M.; PANOBIANCO, M.; POSSAMAI, E.; KOEHLER, H. S. Antecipação da colheita na qualidade fisiológica de sementes de soja. Bragantia, Campinas, v. 68 , n. 3, p. 765-773, 2009. DOI: http://dx.doi.org/10.1590/S0006-87052009000300025

TOLEDO, M. Z.; CAVARIANI, C.; FRANÇA NETO, J. B. Qualidade fisiológica de sementes de soja colhidas em duas épocas após dessecação com glyphosate. Revista Brasileira de Sementes, Londrina, v. 34, n.1 p. 134-142, 2012. DOI: http://dx.doi.org/10.1590/S010131222012000100017

TSUKAHARA, R. Y.; FONSECA, I. C. B.; SILVA, M. A. A.; KOCHINSKI, E. G.; PRESTES NETO, J.; SUYAMA, J. 
T. Produtividade de soja em consequência do atraso da colheita e de condições ambientais. Pesquisa Agropecuária Brasileira, Brasília, v. 51, n. 8, p. 905-915, 2016.

XAVIER, T. S.; DARONCH, D. J.; PELÚZIO, J. M.; AFFÉRRI, F. S.; CARVALHO, E. V.; SANTOS, W. F. Época de colheita na qualidade de sementes de genótipos de soja. Comunicata Scientiae, Bom Jesus, v. 6, n. 2, p. 241-245, 2015.

DOI:

http://dx.doi.org/http://dx.doi.org/10.14295/cs.v6i2.752 